\title{
8 \\ Internet GIS for the Water Industry
}

Uzair (Sam) Shamsi

The Internet is the fastest growing and most efficient technology for distributing GIS data to the public. The Internet and the Web are simplifying how maps are created and maintained. The Internet is facilitating GIS data sharing between different organizations. Intranets are making it easy to share the GIS data between the different co-workers of the same organization. Until recently, spatial information was distributed via the Internet as static map images. Today, dynamic GIS web pages allow the public to interactively display and query GIS databases. Internet-based mapping applications are also changing the way that people use and manage geographic information for their water, wastewater, and stormwater systems. This chapter provides information for serving water resources data on the Internet using GIS. The major topics discussed in this chapter include: Internet GIS data, Internet GIS software, and Internet GIS case studies.

Ed. Note: For brevity and readability, acronyms have been used without their full title, and are instead defined in Table 8.1 overleaf (and in the list of acronyms at the end of the book).

\subsection{Internet GIS Data}

GIS data have never been as easily available as they are today. The Internet has become a popular medium for the electronic dissemination of GIS data to the public. The emergence of Internet technologies in the past few years has made it much easier for geographic data publishers to distribute their data to GIS users. For example, the United States Government has switched from distribution

Shamsi, U.M. 2003. "Internet GIS for the Water Industry." Journal of Water Management Modeling R215-08. doi: 10.14796/JWMM.R215-08.

(C) CHI 2003 www.chijournal.org ISSN: 2292-6062 (Formerly in Practical Modeling of Urban Water Systems. ISBN: 0-9683681-7-4) 
of data on clumsy and expensive reel-to-reel tapes to the Internet, with most data now available on the Web (Thrall, 2001). According to the GIS industry experts, the Internet will continue to be the data delivery medium of choice in the future. Most Internet GIS data are available in digital formats, which can be used directly in GIS applications. Some data formats require minor preprocessing to convert the Internet data into a GIS-compatible (GIS-ready) format. The Internet provides two types of GIS data, (i) public domain data, and (ii) commercial data.

Table 8.1 Acronyms used in this chapter.

\begin{tabular}{ll}
\hline Acronym & Expanded Form \\
\hline AM/FM & Automated Mapping / Facilities Management \\
CAMS & Calibrated Airborne Multispectral Scanner \\
CSO & Combined Sewer Overflow \\
DEM & Digital Elevation Model \\
DFIRM & Digital Flood Insurance Rate Map \\
DLG & Digital Line Graph \\
DOQ & Digital Orthophoto Quadrangle \\
DOQQ & Digital Orthophoto Quarter Quadrangle \\
DRG & Digital Raster Graphic \\
ESRI & Environmental Systems Research Institute \\
HUC & Hydrologic Unit Code (watershed boundaries) \\
LULC & Land Use/Land Cover \\
NED & National Elevation Dataset \\
NGDC & National Geospatial Data Clearinghouse \\
NHD & National Hydrography Dataset \\
NLCD & National Land Cover Database \\
NRCS & Natural Resources Conservation Service \\
PASDA & Pennsylvania Spatial Data Access \\
PDA & Personal Digital Assistants \\
SSURGO & Soil Survey Geographic \\
STATSGO & State Soil Geographic \\
TIGER & Topologically Integrated Geographic Encoding Referencing System \\
USGS & United States Geological Survey \\
UTM & Universal Transverse Mercator \\
\hline
\end{tabular}

\subsubsection{Public Domain GIS Data on the Internet}

Public domain data are nonproprietary data developed by government agencies for public use. A large number of federal, state, and local governments are willing and eager to share their existing GIS data. These data are often free when available online or for the cost of media when shipping is necessary. Table 8.2 provides a summary of main public domain data sites that provide water resources GIS data for the United States. 
Table 8.2 Main public domain data sites for United States GIS data.

\begin{tabular}{|c|c|c|}
\hline Organization & Data & Web Site \\
\hline USGS & $\begin{array}{l}\text { DEM } \\
\text { DRG } \\
\text { DOQ } \\
\text { DLG } \\
\text { LULC } \\
\text { NED } \\
\text { NLCD } \\
\text { NHD } \\
\text { HUC } \\
\text { Reach Files (Rivers) }\end{array}$ & $\begin{array}{l}\text { Earthexplorer.usgs.gov } \\
\text { nsdi.usgs.gov/ } \\
\text { edcwww.cr.usgs.gov/docledchomel } \\
\text { ndcdb/ndcdb.html } \\
\text { edcftp.cr.usgs.gov } \\
\text { dss1.er.usgs.gov } \\
\text { www-nmd.usgs.gov }\end{array}$ \\
\hline USEPA & $\begin{array}{l}\text { LULC } \\
\text { TIGER/Line data for } \\
\text { census tracts and blocks } \\
\text { and geographic features }\end{array}$ & www.epa.gov/enviro/index java.html. \\
\hline $\begin{array}{l}\text { U.S. Census } \\
\text { Bureau }\end{array}$ & $\begin{array}{l}\text { E-MAPS (interactive on- } \\
\text { line maps) }\end{array}$ & www.census.gov/geo/www/tiger/index.html \\
\hline FEMA & $\begin{array}{l}\text { DFIRM } \\
\text { Digital Q3 flood data }\end{array}$ & www.fema.gov/MSC/index.htm \\
\hline NRCS & $\begin{array}{l}\text { SSURGO soils data } \\
\text { STATSGO soils data }\end{array}$ & $\begin{array}{l}\text { www.ftw.nrcs.usda.gov/ssurgo ftp } 3 . h t m l \\
\text { www.ftw.nrcs.usda.gov/stat data.html }\end{array}$ \\
\hline
\end{tabular}

\section{GIS Data Geoportals and Clearinghouses}

GIS users may find it difficult and time consuming to locate the right kind of data for a project for one or more of three reasons:

1. not knowing where to find the data;

2. not finding the right data; or

3. being overwhelmed with the Internet information (i.e. finding too much data).

Too much information is a problem, and though the Internet brings a world of GIS data to a desktop, it is still up to the users to select the right data. GIS data clearinghouses and "Geoportals" help a user sort through the mass of information uncovered while looking for GIS data on the Internet.

One of the best ways to discover GIS data is through geographic clearinghouses and other geographic data sites on the Internet. Some regional organizations act as clearinghouses for local government data or are responsible for unifying GIS data for a region. Clearinghouses promote a more open market in which GIS data with superior characteristics can be selected over inferior data. State, regional, nonprofit, and professional mapping and spatial data clearinghouse Web sites are the most valuable source of free local spatial data. 
PASDA (www.pasda.psu.edu) is an excellent example of a GIS data clearinghouse. PASDA is Pennsylvania's official geospatial information clearinghouse that provides free downloads of DRG, DEM, DOQ, roads, streams, watersheds, river conservation plans, and satellite imagery data for the entire state of Pennsylvania. PASDA supports search, display, and retrieval of GIS data, satellite images, aerial photographs, and metadata related to Pennsylvania. PASDA has made searching for GIS data easy. There are many ways to search for data on PASDA. Data Download will take you to their data catalog which is a list of PASDA data by provider. Keyword search is a default Boolean "and" search that allows you to combine words and narrow your search. For example, you may search for watershed-related data simply by typing in the word "watershed" in the keyword search box. To narrow your search, you may combine "watershed" with "monitoring" to retrieve only those data sets containing watershed monitoring data. Browse by Topic capability allows you to browse the data catalog by subject such as transportation, demography, and environment. In addition, PASDA has created three map-based searchescounty, USGS quadrangle, and watershed. These searches retrieve all data relevant to the selected county, quad, or watershed. Figure 8.1 shows how users can point-and-click on the USGS quadrangle boundaries overlayed on the state map to retrieve the available GIS data for that quad.

NGDC is a collection of more than 100 spatial data servers that have digital geographic data primarily for use in GIS, image processing systems, and other modeling software. NGDC provides search tools to locate GIS data on servers throughout the world. NGDC includes more than 200 sites and thousands of data sets (Lanfear, 2000). These data collections can be searched through a single interface based on their descriptions, or "metadata."

\section{Geography Network}

ESRI's Geography Network (www.geographynetwork.com) provides both free and commercial GIS data on the Internet. The Geography Network is a global network of geographic information users and providers. It provides the infrastructure needed to facilitate the sharing of geographic information between data providers, service providers, and users around the world. The Internet is used to deliver geographic content to the user's browser and desktop. Through the Geography Network, one can access many types of geographic content including live maps, downloadable data, and more advanced services. The site features a mini-browser and software that can combine data from maps of different sources. The network allows users to access GIS data from numerous sources. The USGS and U.S. EPA are two of the government 


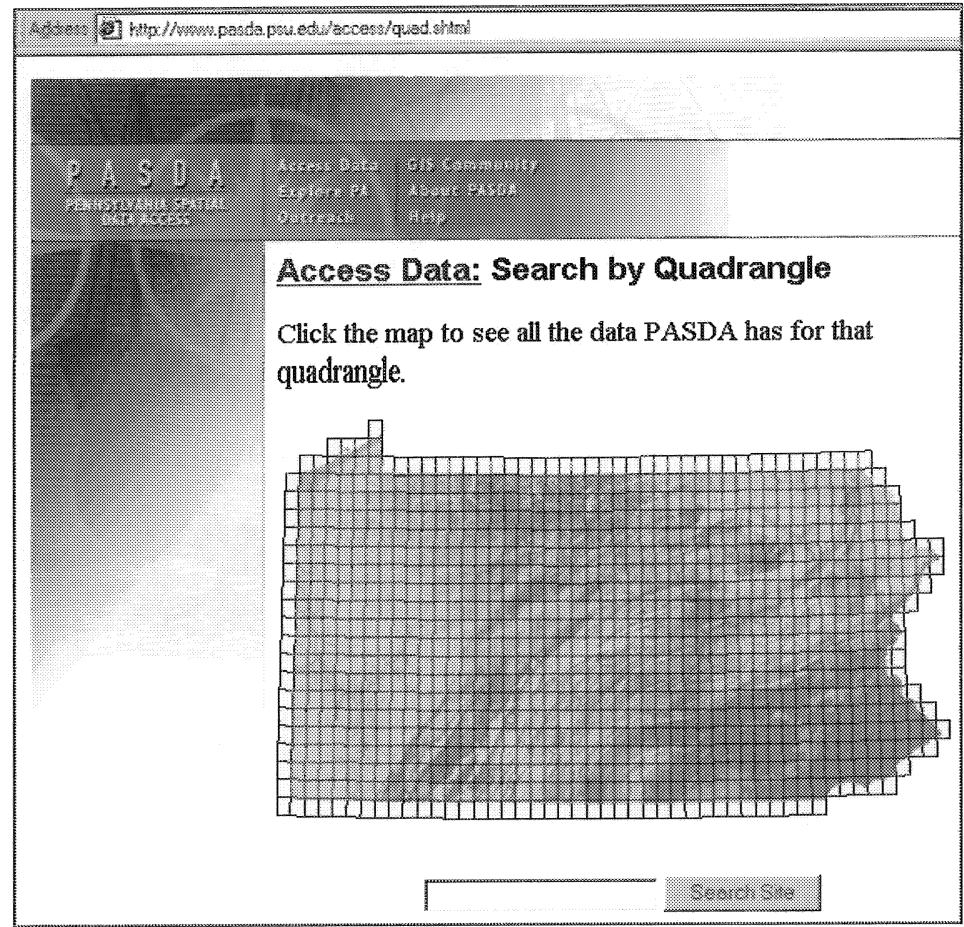

Figure 8.1 Map-based search method used by Pennsylvania Spatial Data Access (PASDA - www.pasda.psu.edu).

contributors to the Geography Network. Among its available GIS data are satellite image, land use, vegetation, flood risk zones, elevation, socioeconomic, and political data layers. Figure 8.2 shows a Flood Risk Map for Pittsburgh, Pennsylvania created using the Geographic Network. Geography Network also provides a collection of links to some of the more useful clearinghouse sites offering data that works with GIS software.

There are many clearinghouse Web sites providing free GIS data. Some sample U.S. and international Web sites are listed in Table 8.3.

\subsubsection{Commercial GIS Data on the Internet}

When opting for free, public-domain GIS data, users should be aware of data quality, file format, GIS compatibility, map projection, Internet download times (if applicable), and data storage issues. Evaluation of these factors may sometimes favor purchasing commercial GIS data. For example, the cost of 


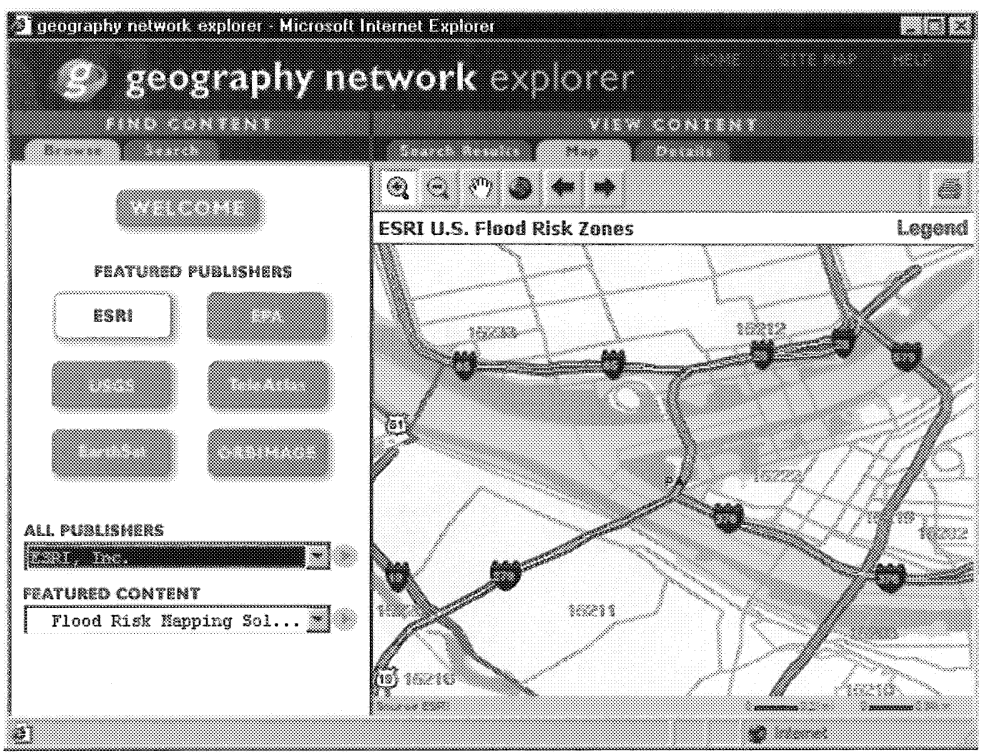

Figure 8.2 Flood risk map for Pittsburgh, Pennsylvania prepared using Geography Network.

Table 8.3 Examples of Clearinghouses and Geoportals.

\begin{tabular}{ll}
\hline Clearinghouse & Web Site \\
\hline Canadian Geospatial Data Infrastructure & ceonet.ccrs.nrcan.gc.ca/ \\
Center for International Earth Science Information & www.ciesin.org/data.html \\
Network (CIESIN) & \\
Directions Magazine Data Center & www.directionsmag.com/datacenter \\
FGDC Clearinghouse Gateway & fgdclearhs.er.usgs.gov/ \\
Geography Network & www.geographynetwork.com \\
Georgia Spatial Data Infrastructure & gis.state.ga.us \\
GIS Data Depot & www.gisdatadepot.com \\
Global Spatial Data Infrastructure (GSDI) & www.gsdi.org \\
Iowa Department of Natural Resources Natural & www.igsb.uiowa.edu/nrgis/ \\
Resources GIS (NRGIS) Library & gishome.htm \\
& www.fgdc.gov/data/data.html \\
National Geospatial Data Clearinghouse & njgeodata.state.nj.us \\
New Jersey Spatial Data Clearinghouse & www.nysgis.state.ny.us/index.html \\
New York State GIS Clearinghouse & www.pamagic.org \\
Pennsylvania Mapping and Geographic & \\
Information Consortium (PaMAGIC) & www.spatialhydrology.com \\
Spatial Hydrology & www.tnris.state.tx.us \\
Texas Natural Resources Information System &
\end{tabular}


geocoding in-house the public-domain street data may exceed the cost of commercial geocoded street data. Other benefits of commercial data are technical support, product updates, and free data upgrades.

Although commercial data costs money, they are usually more usable because they have already been reformatted to a GIS-ready format and, in many instances, they are more current. It can be "penny wise and pound foolish" to automatically reject commercial data because of cost. Free data are not always free. Users can spend much time downloading, converting, cleaning, optimizing, and enhancing data before using them. Commercial data are often immediately usable and often include enhancements not available from public domain sources (Thoen, 2001). Moreover, the cost of spatial data is falling rapidly because of competition in data acquisition, processing, and distribution.

Etak (www.etak.com) is the premier publisher of highly-accurate map data, real-time traffic information, and advanced mapping technology in the United States. According to Etak, they do not simply repackage government data. Their digital databases are developed using a unique and meticulous integration of a wide variety of sources, including aerial photographs, ZIP+4 files, field data capture, and TIGER. For example, Etak data shows highway width, ramps, and one-way streets. EtakMap Premium Digital Map Data contains the complete nationwide network of roadways, extensive points-ofinterest listings, political boundaries, and more than 100 additional attributes. These data are available in MapAccess, shapefile, MapBase, and MapInfo formats. EtakGuide is a route guidance and travel guide CD-ROM for in-car navigation systems.

There are many commercial data vendors, not all of which can be listed here. Geospatial Solutions Magazine's Web site (www.geospatial-online.com/ geospatialsolutions/) maintains an alphabetical list of GIS data vendors that can be accessed from the "Buyers Guide" link of the site. GEOWorld Magazine's home page (www.geoplace.com) also provides a list of geospatial data vendors and their products in a matrix format. Many data vendors allow data downloads or subscriptions for a fee that can be charged to a credit card. Some representative examples of commercial data vendors and their main products are given in Table 8.4 .

\subsubsection{Internet Data Limitations}

Although large volumes of public domain and commercial data for water resources applications are available on the Internet, there may be some problems such as: 
Table 8.4 Examples of commercial data vendors.

\begin{tabular}{ll}
\hline \multicolumn{1}{c}{ Data Vendor } & \multicolumn{1}{c}{ Web Site } \\
\hline $\begin{array}{l}\text { ChartTiff: collarless / seamless USGS DRGs, } \\
\text { DEMs, and DOQs }\end{array}$ & www.charttiff.com \\
ETAK: U.S. roads, extensive points-of-interest & www.etak.com \\
listings, political boundaries, and more than 100 & \\
additional attributes & \\
LANDINFO International: global, digital, & www.landinfo.com \\
topographic and DEM databank for the entire USA & \\
and over 60 other countries in 10 different formats & \\
Map Mart: USGS DEMs, DRGS, and DOQs, (free & www.mapmart.com \\
100K and 250K collarless DRGs) and TIGER data & \\
in MapInfo and ArcView formats & \\
Natural Systems Analyst, Inc.: DOQQ, IKONOS, & www.gisl.com \\
and Landsat 7 imagery & \\
National Geographic: Digital USGS TOPO! maps & www.nationalgeographic.com/topo/ \\
TopoDepot: CAD and GIS vector 7.5-minute & www.topodepot.com \\
topographic quadrangles of the continental United & \\
States and Hawaii & \\
TopoZone: custom topographic maps & www.topozone.com \\
\hline
\end{tabular}

- inadequate resolution,

- inadequate scale,

- inadequate accuracy,

- outdated data,

- incompatible data format, and

- inappropriate projection (coordinate) system.

A successful GIS application requires data accuracy, data integrity (also called referential integrity), and multiple attributes capability (Singh, 1995). Thus, users should be aware of the scale, resolution, accuracy, quality, and intended use of Internet data before using them in their GIS application projects. For example, most federal and state agency maps have small scales $(1: 24,000$ $1: 250,000)$ that may not be suitable for small study areas. Widely available and popular USGS DOQs have a horizontal resolution of $1 \mathrm{~m}$, which may not suit all types of GIS applications. Government agency maps of rapidly growing areas may quickly become outdated, being updated on multiyear cycles.

There are approximately 50 different GIS data formats, not all of which can be read directly in a GIS. For example, U.S. Census Bureau TIGER/Line data format cannot be read in most GIS packages, unless it is converted to one of the standard GIS formats. Government data may be projected using a projection system appropriate for large areas that may not be appropriate for small areas. When opting for free Internet download, GIS data users should be 
aware of long data download times. Download times can span several hours for large files (e.g. USGS DOQ images) when using slow modem connections.

The accuracy of most public domain data depends on the application for which those data were originally collected. In these situations, users should be aware of the intended use and accuracy of such data. For example, the USDA soil maps were originally developed to aid farmers in planning their crops. Soil maps, however, have wide use for very different applications, such as hydrologic modeling. Similarly, US EPA's STORET data represent point water quality data, which are typically extrapolated to represent water quality of an entire stream reach (Griffin, 1995). This is an example of point features data being used to describe line features. Such extrapolations are not necessarily wrong, but users should remember the limitations of their data when interpreting the GIS maps and using them for decision-making.

\subsection{Internet GIS Software}

Until recently, spatial information was distributed via the Internet as static map images which had limited application. Today, dynamic GIS web pages allow the public to interactively display and query GIS databases (Wild and Holm, 1998).

The object RDBMS spatial extensions, such as Oracle Spatial Cartridges, facilitate linking data warehouses with GIS software packages. RDBMS are especially well suited for Internet and intranet data sharing. A data mining application can translate Internet requests into RDBMS queries and send RDBMS responses back to the Internet as Web pages. Utilities that rely on large and complex spatial datasets could greatly benefit from the recent fusion of object RDBMS and the Internet technologies (Lowe, 2000).

Geospatial and enterprise database management systems can be combined to create geospatial data warehouses. For example, using the power of Oracle's spatial extensions, a data mining software can mine your network inventory model from your AM/FM/GIS and make it readily available to the enterprise using the Web. Internet GIS uses a client-server architecture. Therefore, two types of software are required to Web enable a GIS: client-side and server-side.

\subsubsection{Client-side Software}

Client-side software is very easy to use but does not provide data creation or editing capability. It is basically a collection of data browsing tools. It is usually provided free with the purchase of server side software. Examples include: 
- ArcExplorer from ESRI,

- GeoMedia Viewer from Intergraph, and

- MapGuide Viewer from Autodesk.

\subsubsection{Server-side Software}

Server-side software, accessible through browsers, makes GIS usable over the Web. Based on the capabilities, the cost ranges from US\$5-25,000. Examples include:

- ArcIMS and RouteMap IMS, ESRI

- GeoMedia Web Map, Intergraph

- MapGuide, Autodesk

\subsection{Internet GIS Data Case Studies}

\subsubsection{Development of a Collection System Inspection Database}

The Municipal Authority of the City of Monongahela (MACM) located in Washington County, Pennsylvania serves a population of 4,900. Sewage treatment is provided by a 1.5 MGD sewage treatment plant. During 20002001, USFilter Engineering \& Construction (Pittsburgh, Pennsylvania) created a GIS database using various Internet public domain data sources listed above to support MACM's collection system improvement and CSO abatement activities. MACM's GIS project involved eight tasks:

1. develop manhole/sewer line coverages from existing CAD files;

2. add manhole attributes from manhole inspection reports;

3. add sewer attributes from TV inspection logs;

4. develop service laterals coverage from TV inspection logs;

5. develop video coverage from TV inspection tapes;

6. add street names to the existing roads coverage;

7. align image and feature themes; and

8. package the information for delivery.

Software, hardware, and data used in this project are listed below:

Software

Hardware

Public Domain GIS data
ArcInfo, ArcView, Microsoft Excel

Windows NT workstation, Windows 98 PC, HewlettPackard DeskJet $1220 \mathrm{c}$ printer and DesignJet $650 \mathrm{c}$ plotter USGS digital raster graphics (DRG), digital elevation models (DEM) and digital orthophoto quadrangles (DOQ) 
Figures 8.3 and 8.4 show the ArcView GIS layers overlayed on USGS topographic maps (DRG) and aerial photographs (DOQ), respectively. Thanks to quick and free availability of the Internet GIS data, the project was completed in six months for a cost of US\$15,000 (Shamsi, 2001; Shamsi, 2002; www.GISApplications.com).

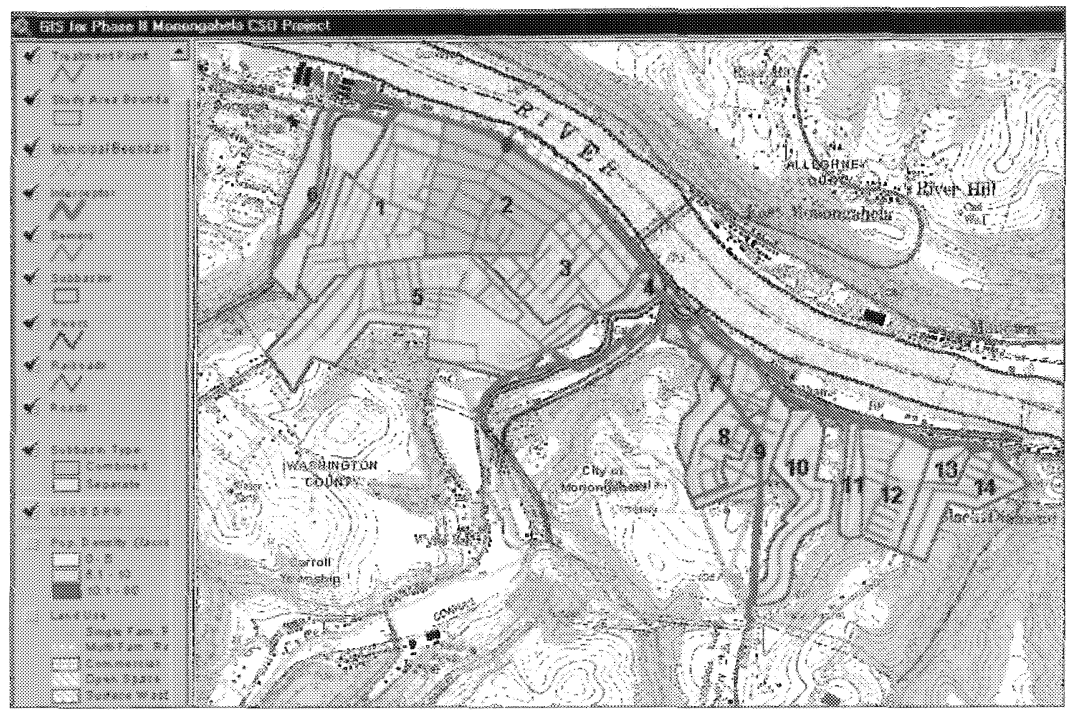

Figure 8.3 Sewershed boundaries and sewers overlaid on a USGS DRG basemap.

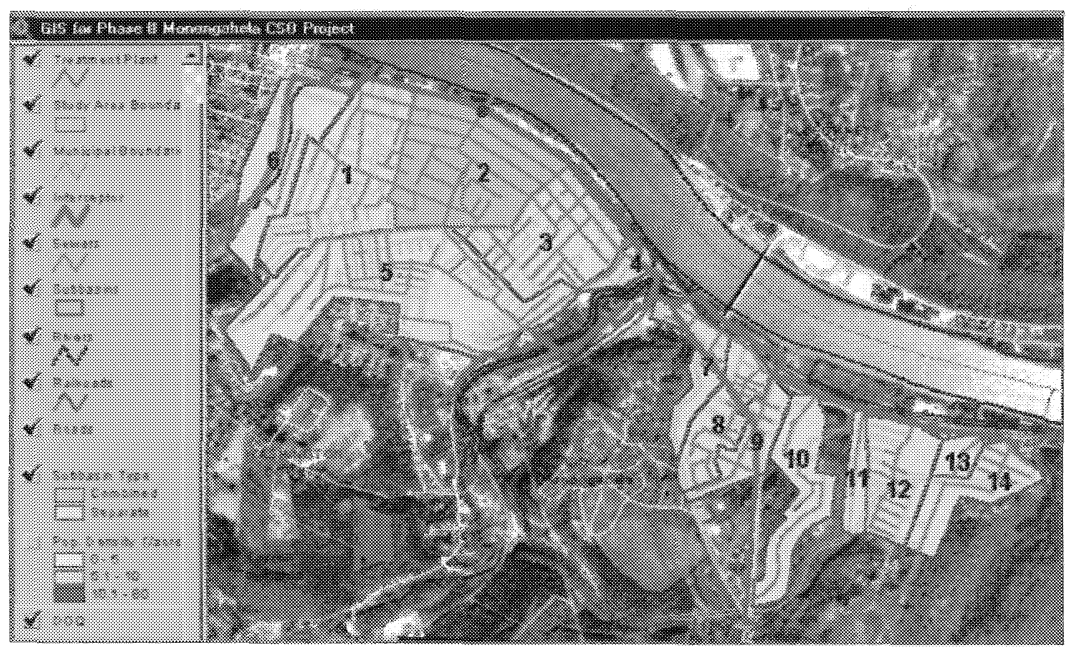

Figure 8.4 Sewershed boundaries and sewers overlaid on a USGS DOQ basemap. 


\subsubsection{Development of a Surface Water Quality GIS Database}

A large amount of fertilizer, herbicides, and pesticides applied yearly to the lands in the Mississippi River basin contribute to algal blooms, as some residual chemical breakdown of the compounds contained in agricultural runoff function as nutrient components. In response to concerns of algal bloom and water quality, a research consortium integrated millions of data records from hundreds of sources to construct a massive GIS for the Mississippi River basin. The main objective of the research study was to develop a water-quality parametric database to characterize the river, using historical and contemporary water quality data and a GIS. The project team developed a relational database of water quality parameters and integrated the parametric data into ArcView. GIS data for the basemap were obtained from multiple public-access Internet sites. Much of the data were downloaded as DLG files, and converted to vector coverages and shapefiles. Visual evaluation of GIS maps answered many questions. For example, are high dissolved nitrogen locations located near a land use change area? Or are they near an industrial complex? If yes, then what type of industry? Highlights of the GIS database are as follows (Swalm et al., 2000):

- Projection system: UTM zone 15

- Basemap: 1:2,000,000-scale layers of road, railroad, political boundary, and hydrography

- $1: 100,000$-scale USGS DLGs

- 1:250,000-scale USGS land use/land cover (LULC)

- USGS DEMs

- NRCS STATSGO soils

- 60-m multispectral satellite imagery from USGS from the 1970s, 1980s, and 1990s

- Parametric database: 1.3 million records on 700 parameters

Software, hardware, and data used in this project are listed below:

Software

Hardware

Public Domain GIS data

Commercial GIS data
ArcInfo, ArcView, ERDAS, Oracle 8i, SAS

SUN Microsystems Sparc 1000 and Sparc 20 workstations, Dell Precision 400 workstations, Gateway 200 personal computers, Hewlett-Packard $1000 \mathrm{c}$ printer and $H P 755 \mathrm{~cm}$ plotter

USGS DRG, DLG, and DEM data and NRCS STATSGO data USGS 60-m resolution satellite imagery, NASA 5-m resolution CAMS imagery 


\subsubsection{Web-based Utility Mapping}

One of the fastest-growing communities in the Midwest United States, Dublin $\left(22 \mathrm{mi}^{2}\right.$ in area) is home to about 30,000 people and 2,500 businesses. The city received the Best Practices Award in the year 2000 from the Ohio Geographically Referenced Information Program, a state agency responsible for educating local government about GIS technology. The city is constantly enhancing its GIS capabilities and serves as a model medium-sized municipal GIS for the state. This application was developed after the City personnel realized that retrieving data from hard-copy records was inefficient because it reduced staff time for engineering review and analysis. They needed an automated system that could recall, evaluate and reproduce data more quickly. They implemented a Web-based GIS data server using Autodesk Inc.'s (San Rafael, Calif.) Webbased MapGuide technology.

Dublin's GIS Web site (gis.dublin.oh.us) provides quick access to water, wastewater, and stormwater utility data for maintenance, planning and emergency response activities. A screenshot of the Web site is shown in Figure 8.5. Dublin also moved much of the GIS mapping and city assets to a mobile environment with wireless technology and GPS to allow data products to be distributed to a mobile workforce with PDAs and wireless notebooks. The future is expected to bring even more integration between traditional municipal applications and GIS because the city also plans to integrate other applications, including work orders, asset management, crime analysis, public safety and

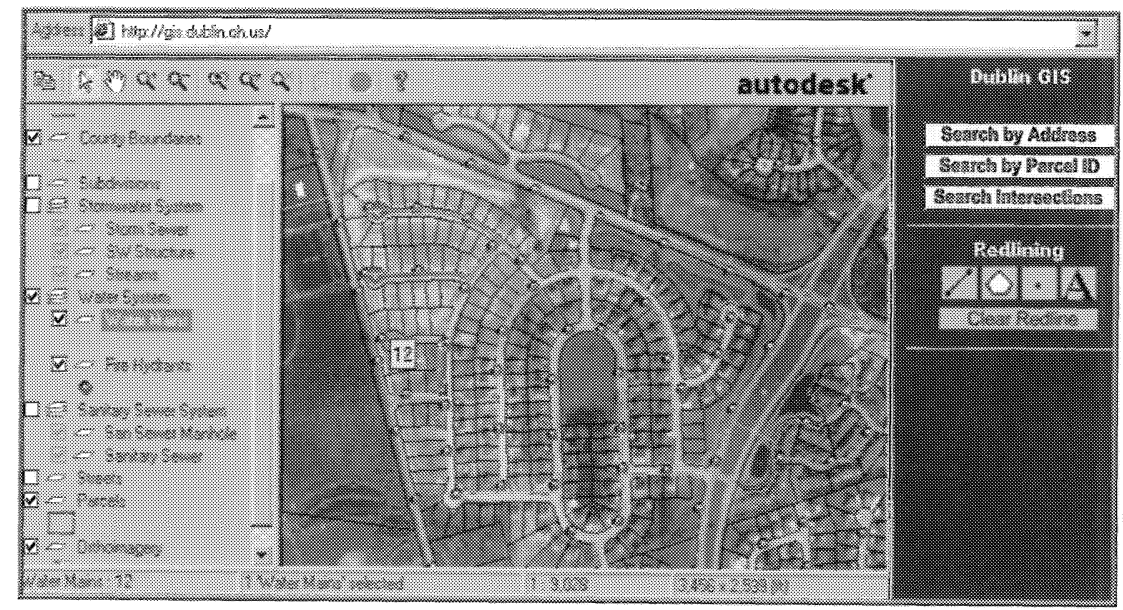

Figure 8.5 Dublin's (Ohio) utility web server (http://gis.dublin.oh.us/). 
emergency dispatch. Determining how much money this technology is saving the city is difficult to assess. However, the City feels that in most cases, the time and effort required to respond to utility data requests have decreased from several hours to minutes, which translates to increased staff productivity and enhanced responsiveness to customers (Cerasini and Herskowitz, 2001).

Software and data used in this project are listed below:

\begin{tabular}{|c|c|}
\hline GIS software & AutoCAD, AutoCAD Map, MapGuide \\
\hline GIS data & $\begin{array}{l}\text { 1-m, natural color, orthorectified, precision pan-sharpened imagery of } \\
\text { the entire city from Space Imaging (Thornton, Colorado, USA); and } \\
\text { vector layers for school districts, corporate limits, county boundaries, } \\
\text { subdivisions, streets, parcels, and water (mains and hydrants), } \\
\text { stormwater (sewers, structures, and streams), and sanitary sewer (sewers } \\
\text { and manholes) systems. }\end{array}$ \\
\hline area & City of Dublin (Ohio), USA \\
\hline
\end{tabular}

\subsection{Conclusions}

The Internet is the fastest growing and most efficient technology for distributing GIS data. Internet can be used to both obtain and distribute GIS data. Webservers are very useful in distributing water utility GIS data. Internet-based mapping applications are changing the way people use and manage geographic information for their water resources projects. Local and regional GIS data clearinghouse Web sites are very useful for obtaining water resources data. "Free" Internet data may not always be free because they may require preprocessing time to make them ready for GIS. In these cases, commercial data sites that provide enhanced GIS-ready data are a better source.

Despite the many advantages of the Internet GIS, users should be aware of the limitations of GIS data available there. The limitations of the internet data stem from their intended use and accuracy of their source data. Some Internet GIS data may have inadequate resolution, scale, or accuracy for a particular project need. They might be outdated and incompatible or have an inappropriate projection (coordinate) system. Thus, data quality and accuracy should be evaluated in the context of the GIS application in which the data will be used.

\section{References}

Cerasini, V and J. Herskowitz (2001). City Streamlines Customer Service. Imaging Notes, Space Imaging, Thornton, CO, Vol. 16, No. 5, Sept/Oct 2001, 26-27. 
Griffin, C.B. (1995). Data Quality Issues Affecting GIS Use for Environmental Problem-Solving. Proceedings of the National Conference on Environmental Problem-Solving with Geographic Information Systems, EPA/625/R-95/004, Office of Research and Development, United States Environmental Protection Agency, Cincinnati, Ohio, September 1995, 15-30.

Lanfear, K. J. (2000). The Future of GIS and Water Resources. Water Resources Impact, American Water Resources Association, Volume 2, Number 5, September 2000,9-11.

Lowe, J.W. (2000). Utilities Databases Internet. Geo Info Systems, March 2000, 4648.

Shamsi, U.M. (2001). Municipal Authority of the City of Monongahela GIS Data Enhancements, USFilter Engineering \& Construction, Pittsburgh, Pennsylvania. www.GISApplications.com.

Shamsi, U.M. 2002. "GIS Applications in Inspection and Maintenance of Collection Systems." Journal of Water Management Modeling R208-14. doi: 10.14796/JWMM.R208-14.

Singh, V.P. (Editor) (1995). Computer Models of Watershed Hydrology. Water Resources Publications, 1130 pages.

Swalm, C., J.T. Gunter, V. Miller, D.G. Hodges, J.L. Regens, J. Bollinger, and W. George (2000). GIS Blossoms on the Mighty Mississippi. Geo Info Systems, April 2000, 30-34.

Thrall, G. I. (2001). Business Geography Data Resources - Part 2. Geospatial Solutions, Volume 11, No. 6, June 2001, 44-49.

Thoen, B. (2001). Maximizing Your Search For Geospatial Data. GEOWorld, Volume 14, No. 4, April 2001, 34-37.

Wild, M. and D. Holm (1998). Consensus Building at Superfund Sites Using GIS. Proceedings of the 1998 National Conference on Environmental Engineering, Edited by T. E. Wilson, ASCE, June 7-10, 1998, Chicago, Illinois, pp:326-331. 
